\title{
La psicológía de Henri Wallon y su relevancia para el estudiodel trabajo y de la actividad
}

\author{
Juan Ignacio Castien Maestro ${ }^{1}$
}

Resumen: La obra de Henri Wallon (1879-1962) representa un valioso esfuerzo por construir una psicología materialista y dialéctica. Apesar de todo este potencial, la psicología walloniana disfruta hoy en día de una popularidad bastante inferior a la de otras psicologías también de raigambre marxista como el freudomarxismo y la escuela de Vygotsky. En este breve artículo pretendemos contribuir a un mejor conocimiento de la misma, así como destacar su fecundidad para el estudio de la naturaleza y la génesis de diversos tipos de actividad humana como el juego, el arte, el ritual mágico-religioso, la ciencia y el trabajo. Centrándonos en el trabajo, entendido en un sentido moderno, éste difiere de otras formas históricamente anteriores de actividad laboral, por su mayor objetividad y su menor emotividad. La objetividad puede entenderse en un sentido cercano al de la descentración de Piaget, como una distinción entre el sujeto y el mundo objetivo sobre el cual actúa aquél. Estas cualidades son el resultado de un largo proceso histórico. La teoría de Wallon sobre la imitación, como vehículo para la construcción de las emociones y del conocimiento objetivo de uno mismo y del medio, puede iluminar algunos aspectos de este complejo proceso.

Palabras clave: Wallon; imitación; trabajo.

Abstract: The work of the french psychologist Henri Wallon (18791962) represents a valuable effort to build up a dialectical materialist psychology. Despite all its potential, Wallonian psychology is currently

${ }^{1}$ Coordinador del Master de Psicología Social de la Universidad Complutense de Madrid, Facultad de Ciencias Políticas y Sociología, Campus de Somosaguas. E-mail: jicastie@ucm.es. 
quite far from being as popular as other schools of marxist roots, such as Freudo-Marxism and Vygotsky's approach. In this paper we wish to contribute to a better understanding of it, as well as to highlight its fruitfulness in relation with the study of nature and the genesis of different types of human activity such as play, art, magic-religious ritual, science and work. Focusing on work, in its modern meaning, this differs from other historically previous forms of labour activity because it is more objective and less emotional. Objectivity can be understood in a sense which is close to that of Piaget's theory of decentration, that is to say, as a distinction between the individual and the objective world on which he acts. These qualities are the result of a long historical process. Wallon's theory about imitation as a vehicle in the building of emotions, objective knowledge of the environment and self-awareness, may throw light upon some aspects of this complex process.

Key words: Wallon; imitation; work.

\section{La psicología de Henri Wallon ante las distintas formas de actividad humana}

La obra de Henri Wallon (1879-1962) representa un encomiable esfuerzo por construir una psicología materialista y dialéctica. Las investigaciones de este autor se centraron ante todo en el desarrollo intelectual y emocional del niño, lo que le condujo a un prolongado y fructífero debate con Jean Piaget, un psicólogo cuya afinidad con algunos postulados del marxismo resulta también notoria. Al igual que aquél, Wallon elaboró una teoría muy compleja acerca de la génesis del pensamiento abstracto a partir de la actividad práctica. La originalidad de su enfoque reside, sin embargo, en la gran relevancia que él concede a la imitación y al manejo de las emociones ligadas a la misma. Este relativo cambio de énfasis le permite desentrañar algunos nuevos mecanismos concretos a través de los cuales podría tener lugar la determinación general de la conciencia por el ser social postulada por el materialismo histórico. A esta primera virtualidad se añade además un

120 La psicológía de Henri Wallon y su relevancia para el estudio... 
afán constante por superar esa barrera artificial entre lo cognitivo y lo emotivo erigida por tantas otras teorías psicológicas (WALLON, 1985, 1987, 2008). A pesar de todo este potencial, la psicología walloniana disfruta hoy en día de una popularidad bastante inferior a la de otras psicologías también de raigambre marxista como el freudomarxismo y la escuela de Vygotsky. En este breve artículo nos gustaría, por ello, contribuir, en la medida de lo posible, a un mejor conocimiento de la misma, así como a destacar su fecundidad en relación con ciertas problemáticas que podrían enriquecerse de un modo decisivo gracias a su concurso.

En concreto, vamos a recurrir a ella para indagar en la génesis y en la naturaleza de diversos tipos de actividad humana, como el juego, el arte, el ritual mágico-religioso, la ciencia y el trabajo. Cada uno de estos tipos de actividad, que raramente se presentan en un estado puro, sino entremezclados con otros, puede ser caracterizado, por supuesto, con arreglo a diversos criterios. A nosotros nos interesan, en una primera aproximación, aquellos que atañen a sus grados de objetividad, emotividad y complejidad. Entendemos su objetividad como lo opuesto al subjetivismo $\mathrm{y}$, en particular, al egocentrismo en un sentido piagetiano, es decir, como un estado de indistinción subjetiva entre el sujeto y el mundo objetivo que le rodea. De acuerdo con el mismo Piaget, este egocentrismo es un rasgo inicial del ser humano, que va siendo luego superado en sus formas más extremas, pero que pervive en ciertas facetas del comportamiento y del pensamiento adulto. Asimismo, su grado de superación efectiva varía notablemente entre individuos, grupos sociales, campos de actividad, períodos históricos y sociedades (PIAGET, 1974, p. 273-343). Por ello, podemos sostener también que las diversas actividades desarrolladas por un mismo adulto van a ostentar igualmente diferentes niveles de centración, lo que supone distinguir en mayor o menor medida entre los efectos de la actividad personal sobre el propio estado de ánimo y aquellos otros que atañen al mundo real. Así, el trabajo moderno y tecnificado constituye una actividad claramente objetivista, en donde 
han de diferenciarse claramente las transformaciones operadas sobre la realidad objetiva de sus repercusiones subjetivas. Lo mismo ocurre con la investigación científica. En el otro extremo, los rituales mágicoreligiosos entrañarían un elevado nivel de egocentrismo, desde el momento en que en ellos se atribuye una eficacia real a unas acciones cuya influencia, en cambio, se ejerce ante todo sobre la psique de las personas involucradas en ellas (CASTIEN MAESTRO, 2008, p. 71-75). De ahí que, como es sabido, en la práctica, algunos de estos rituales puedan contribuir a una reestructuración de la experiencia subjetiva, con resultados muy positivos en el plano individual y colectivo, tal y como ha sido puesto de manifiesto por toda una línea de investigación ya clásica en antropología (cf. LÉVI-STRAUSS, 1987, p. 211-228; LIENHARDT, 1986; MALINOWSKI, 1985; TURNER, 1990, p. 399-440) Entre ambos polos, el arte y el juego ocupan una posición intermedia. En su caso se distingue, en principio, entre la realidad objetiva y la vivencia subjetiva, pero, a menudo, el sujeto acaba reorganizando, de manera en parte intencionada y consciente, su campo perceptivo de un modo tal que, durante un lapso de tiempo, acaba creyendo, hasta un cierto punto, en la realidad de lo que hace y de lo que parece estar ocurriendo, experimentando con ello las emociones pertinentes. Entra, así, en esa lógica del "como si" descrita en su día por Johan Huizinga (1997, p. 11-42).

En lo que respecta a su emotividad y a su complejidad, también puede trazarse una clara frontera entre unas actividades y otras. El trabajo y la investigación científica constituyen, en términos generales, unas actividades más "frías" que las demás, cuyos grados de emotividad son, por otra parte, muy variables. Sin duda, pueden ser ejecutados en ocasiones con una gran pasión, pero, aún así, esta pasión no es el efecto que han de generar necesariamente, al contrario de lo que ocurre con los otros tipos de actividades. Y, asimismo, un exceso de emotividad podría llegar a dificultar su correcta realización. Por último, la complejidad alcanzada por el encadenamiento de actos del que se trate va a variar también mucho. Todas estas actividades

122 La psicológía de Henri Wallon y su relevancia para el estudio... 
pueden ser muy sofisticadas. Pero el juego, como actividad ante todo infantil que luego se prolonga, más o menos según los casos, hasta la edad adulta, tiende a ser en general la más sencilla de todas.

Estas cinco actividades son desarrolladas, en alguna medida, por la inmensa mayoría de los adultos corrientes, si bien a veces no se juega en absoluto, y parte de los adultos no llevan a cabo ritual mágico-religioso alguno, ni tampoco ningún equivalente secular de los mismos, de igual manera que su relación con el arte y la ciencia se reduce a la de meros espectadores. Habida cuenta de que estas cinco actividades estructuran, por tanto, la vida de casi todo el mundo a las mismas edades, se las puede considerar coetáneas. Pero el que lo estén siendo de hecho no implica, sin embargo, que no hayan aparecido en períodos cronológicos diferentes, ni que unas no puedan haber surgido de las otras. En suma, estas distintas actividades pueden diferir no sólo en su naturaleza, sino también en su propio proceso de génesis, entendido éste en un doble sentido. El primero atañe a la génesis en el plano individual, al proceso en virtud del cual se van desarrollando las diversas actividades de cada sujeto en el curso de su existencia personal. Su campo es, pues, el de la psicogénesis, como componente parcial de la ontogénesis. Nuestro segundo sentido apunta, por el contrario, a su génesis histórica, es decir, al proceso histórico a través del que los diferentes colectivos humanos han ido desarrollando estos distintos modos de actividad y los han incorporado a su propio patrimonio cultural, de modo que los nuevos miembros de estos grupos pueden ahora apropiárselos. Ambos procesos de génesis, el individual y el colectivo, son en sí diferentes, pero se encuentran claramente interrelacionados. De una parte, aquellas formas de actividad que ostentan una naturaleza más egocéntrica y menos sofisticada pueden considerarse en ambos casos como más arcaicas y, acaso, como el origen de las demás. De la otra, y más allá de estos paralelismos, conforme el patrimonio cultural de ciertos colectivos humanos se haya ido volviendo más complejo, sus miembros habrán podido también aprender unos modos de actividad más avanzados, vedados para ellos 
en el pasado, como lo están en el presente para otros colectivos cuyo patrimonio cultural es más pobre, cosa que les habrá permitido a su vez proseguir con su desarrollo individual (cf. WALLON, 1987, p. 7684; WALLON, 2008, p. 36).

\section{Imitación, emoción y vivencia}

El conocimiento de estos dos procesos de génesis podría verse enriquecido por el recurso a algunos elementos de la teoría de Wallon sobre las emociones y la imitación (WALLON, 1987, p. 110-149). En opinión de este autor, la principal función de la emoción estriba en la regulación de la actividad. En contraste con los modelos más simples, propios del reino animal, de reacción estereotipada frente a ciertos estímulos prefijados, lo que caracteriza a la actividad específicamente humana es su versatilidad. Esta versatilidad se asienta sobre la autonomización del tono, que hace posible una activación corporal general dotada de una mayor estabilidad temporal en comparación con las conductas puntuales. El tono constituye el fundamento fisiológico objetivo de la emoción. En función de cuál sea aquél en un momento dado, variarán los comportamientos concretos que puedan llevarse a cabo, incluso como respuesta a unos mismos estímulos. De este modo, se establece una entidad mediadora entre los estímulos y las conductas, que proporciona un mayor margen de autonomía con respecto a los primeros (WALLON, 1985, p. 109-128; ZAZZO, 1976, p. 43-50).

Un segundo elemento central dentro del planteamiento walloniano viene dado por la imitación. De acuerdo con nuestro autor, se trata de una actividad clave en el desarrollo intelectual y emocional del ser humano. Aparece en sus formas más simples al poco de nacer y se desarrolla de manera continuada durante toda la vida. Conforme se va volviendo más compleja, va teniendo lugar también una progresiva autonomización del pensamiento con respecto al comportamiento. Aparece así la representación mental independiente de la imitación práctica. De igual manera, una imitación cada vez más ajustada a su

124 La psicológía de Henri Wallon y su relevancia para el estudio... 
modelo exige una observación cada vez más meticulosa del mismo, pero también del propio sujeto que lo imita, lo que desemboca en un conocimiento cada vez más sistemático acerca de ambos. De ahí que constituya uno de los principales modos de elaborar los esquemas de comportamiento y de pensamiento descritos por Piaget y para avanzar en el proceso de descentración. Es también un medio privilegiado para el desarrollo de las emociones. Como acabamos de apuntar, la actividad en general se liga a la emoción y ello ocurre también con esa específica actividad que es la actividad imitativa. De un modo más particular, la imitación favorece la evocación de lo imitado y la concomitante reproducción de las emociones vinculadas al mismo. Imitar actos pasados entraña vivenciarlos de nuevo. Entraña, pues, experimentar una determinada vivencia en la que van a converger representaciones, sensaciones y emociones.

Sin embargo, con el tiempo puede aparecer una imitación "en frío", al igual que una representación imaginativa también "en frío", es decir, una imitación o una representación disociadas de las experiencias emocionales con las que se encontraban inicialmente relacionadas. Ello implica evidentemente una mayor complejidad intelectual. Conduce, asimismo, a una bifurcación entre aquella actividad imitativa y representativa cuyo principal resultado es la experimentación de unas determinadas vivencias y aquella otra que da lugar a un mayor conocimiento objetivo de uno mismo y de lo que se imita. Supone, pues, la bifurcación entre una imitación y una representación promotoras ambas del desarrollo emocional y una imitación y una representación que hacen otro tanto con el conocimiento objetivo. Por otra parte, esta imitación y esta representación pueden volverse también más creativas, combinando elementos integrados originariamente dentro de modelos diferentes en un solo modelo de carácter sintético. Con ello, la diferenciación entre sus formas más vivenciales y las más realistas, entre las más subjetivistas y las más objetivistas, puede acentuarse aún más. Estos avances se vuelven posibles sobre todo porque la imitación se va volviendo además de naturaleza más diferida. Ya no se imita sólo 
lo que se tiene delante, sino acontecimientos ocurridos hace un tiempo y que son reconstruidos de un modo creativo.

En vista de todo lo anterior, la imitación, se nos presenta como un procedimiento privilegiado de apropiación del patrimonio cultural del colectivo humano al que se pertenece. Combinando ahora los planteamientos de Wallon y de Piaget, podemos establecer que las relaciones entre la imitación y el egocentrismo son harto complejas. Cuando el egocentrismo es elevado, el sujeto acostumbra a confundir su realidad con la vivencia que experimenta al imitar algo. En un caso semejante, tiende a identificarse con lo imitado, al menos mientras perdura la imitación. Por el contrario, cuando se han alcanzado niveles superiores de descentración, resulta posible distinguir entre uno mismo y lo imitado o representado, así como las emociones pertinentes en cada caso, lo que conlleva una organización mucho más compleja y sistemática de las propias emociones. Pero este proceso no debe entenderse solamente de un modo unidireccional. La complejización y sistematización progresiva de este sistema puede contemplarse, de manera recíproca, como un avance parcial en el proceso general de descentración referente a una faceta específica de la existencia humana. Y no sólo eso: también como un medio indirecto de incrementar la descentración global, mediante una aplicación sobre otros campos de actividad de aquellos esquemas más complejos desarrollados previamente en esa específica faceta de la propia existencia.

\section{Dramatización y racionalización}

El modelo teórico que acabamos de resumir puede sernos de gran utilidad para entender mejor la génesis de las distintas formas de actividad a las que nos hemos referido en el primer apartado. Este recurso a ciertos elementos de unas teorías psicológicas, como las de Wallon y Piaget, para explicar algunos aspectos de un proceso histórico colectivo no implica de por sí ningún deslizamiento psicologista. Ciertamente, la dinámica social es irreductible a la de la psique

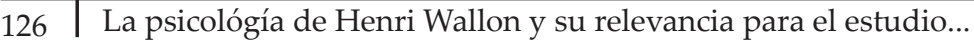


individual, a la cual engloba además en una gran parte. Sin embargo, ello no significa que esta dinámica psíquica no disfrute también de una evidente autonomía relativa, ni que, justamente por esta razón, los distintos procesos que la conforman no hayan de ser estudiados, a fin de entender mejor esos otros procesos sociales más amplios dentro de los cuales se encuentran inmersos.

Guiados por este objetivo, vamos a introducir un nuevo concepto, el de dramatización. Podemos definirla como un encadenamiento de actos que replica situaciones reales o imaginarias, con lo cual se recrea un conjunto de vivencias vinculadas a tales situaciones. La dramatización constituye, así, un tipo particular de imitación, especialmente centrado en el manejo de las emociones, aunque el grado de creencia en la realidad de lo experimentado pueda ser muy variable. Con frecuencia, va a constituir, asimismo, una simple faceta de otras actividades más amplias. Hay actividades en donde este componente dramatúrgico ostenta un peso decisivo, como en el caso del juego, el ritual y el teatro. Por contra, su presencia en el seno de otras como el trabajo racionalizado y moderno y la investigación científica resulta muy poco significativa. Existen, por último, formas mixtas, como suele ocurrir con la actividad productiva tradicional y pre-capitalista, cuya acción transformadora de la realidad objetiva se entremezcla con diversos rituales mágico-religiosos, hecho éste acerca del cual autores clásicos como Mircea Eliade (2004) nos han proporcionado unas descripciones de una extraordinaria riqueza. En el polo opuesto a esta actividad dramatúrgica nos topamos con la actividad instrumental racional. Se halla dirigida a transformar la realidad del modo más eficaz posible, en función de los propósitos de quien la realiza, desentendiéndose de las emociones que pueda generar al hacerlo. Se corresponde básicamente con la acción racional con arreglo a fines delimitada en su día por Max Weber (1964) y, por supuesto, es plenamente objetivista. El trabajo moderno y racionalizado, cuyo paradigma sería el efectuado por un asalariado empleado en una empresa capitalista, constituye su ejemplo más acabado. Se trata de una actividad "enfriada", en donde 
los actos destinados a recrear vivencias han ido siendo eliminados como improductivos en el curso de un largo proceso histórico. Por lo demás, la instrumentalidad no se restringe, por supuesto, a la actividad exclusivamente material, sino que abarca, asimismo, una gran parte de las acciones simbólicas, siempre y cuando el manejo y la construcción de símbolos se encamine a provocar alteraciones objetivas en la realidad, incluyendo aquí a los otros seres humanos, a los cuales se puede influenciar por diversas vías, y no a suscitar unas determinadas emociones entre quienes las están llevando a cabo.

Partiendo de todas estas distinciones preliminares, podemos esbozar un sencillo cuadro comprehensivo para las diversas actividades humanas, que dé cuenta de la específica naturaleza de cada una de ellas y aventure algunas hipótesis acerca de su particular proceso de gestación. Junto con Piaget, creemos que el acceso a un cierto nivel de centración es el fruto de un largo y continuado esfuerzo. Hoy en día su logro por parte del individuo se ve enormemente facilitado por los esquemas culturales, los instrumentos materiales y los modos de relación social legados por todo un desarrollo histórico previo. Se trata de todo un conjunto de herramientas intelectuales, de herramientas para potenciar las distintas funciones psíquicas, en el sentido establecido por Vygotsky (1995). De ahí que en las formas más primitivas de actividad haya tendido a darse, en cambio, una abigarrada mezcolanza entre lo dramático y lo instrumental, como ha sido el caso sobre todo de la actividad productiva tradicional. En virtud de la imposibilidad en la que se encuentra aquí el propio sujeto de determinar con nitidez los efectos reales de sus actos, en lugar de obrar dominado por sus propias fantasías, esta actividad productiva tradicional resulta altamente alienante en el sentido marxista clásico, aunque bajo una modalidad diferente de la que caracteriza al trabajo moderno, tal y como esta última fue descrita por Marx (1972), y ello con independencia también de que el hecho de creerse afincado en un mundo encantado, colmado de significados, pueda redundar quizá en un mayor bienestar psicológico. No en vano, el amplio ejercicio de

128 La psicológía de Henri Wallon y su relevancia para el estudio... 
esta actividad dramatúrgica se corresponde con la preponderancia de un pensamiento mítico. El juego también parece revestir una notable importancia en este estadio más primitivo (HUIZINGA, 1997). Lo que distinguiría a la actividad lúdica de la mágico-religiosa no sería tanto su frecuente menor nivel de sofisticación y de implicación emocional, como su menor conexión con alguna determinada ideología religiosa. El juego es más un fin en sí mismo. Su sentido cósmico es menor y no se toma tan en serio, razón por la cual conlleva un menor grado de egocentrismo, incluso en los niños a partir de una cierta edad. Por ello precisamente, una de las facetas de la secularización consiste en la conversión del rito en juego y del mito en cuento.

El crecimiento de las fuerzas productivas permite y requiere una vida social más rica y elaborada, lo que implica, ante todo, una mayor sofisticación de la actividad bajo sus diferentes formas. De este modo, sus modalidades mágico-religiosas se asocian a unos sistemas ideológicos cada vez más complejos, lo cual puede obstaculizar, por su parte, el desarrollo de sus variantes más instrumentales y racionalizadas, empezando por las más directamente vinculadas a la producción material. Surge también una especulación teológica, relativamente disociada del ritual. Esta progresiva sofisticación de la existencia también se plasma en la eclosión de nuevas formas de actividad, como la artística y la científica. El arte se define por su elaboración a fondo de las emociones asociadas con la imitación y la representación, entendida como un fin en sí mismo, independiente, por tanto, de cualquier propósito práctico, sea éste real o imaginario. Tal es el motivo de que entre en contradicción con las exigencias de la actividad ritual y de los sistemas mitológicos con los que ésta se articula, contradicción que puede acabar propiciando la lucha por su autonomía (LUKÁCS, 1967, p. 368-575; THOMPSON, 1986, p. 83104). Autonomizado del interés por actuar sobre el mundo objetivo de un modo directo, el arte puede entonces desarrollar más a fondo la dimensión estrictamente vivencial. En su doble faceta de producción por parte del artista y de contemplación por parte del espectador, 
el arte constituye un medio privilegiado para profundizar en el conocimiento de la subjetividad propia y ajena y combatir, de este modo, el egocentrismo. En lo que atañe en particular a su dimensión contemplativa, se sirve de un artefacto cultural, la obra de arte, al que podemos considerar como un peculiar género de herramienta intelectual. En cierto modo en el otro extremo, aunque comparta con el arte su nueva complejidad, la ciencia se desarrolla, por su parte, como un intento de representación realista, despojada de componentes dramáticos y disociada de la acción práctica inmediata sobre su objeto. Aunque en ocasiones los esquemas mentales de lo que se sirve puedan haber tenido su origen en representaciones dramatúrgicas, e incluso mágico-religiosas, lo que la distingue como tal ciencia es su capacidad para adaptar esta materia prima a sus propios objetivos.

La modernización capitalista trae aparejada una nueva diversificación de la actividad humana y un desarrollo muy superior de su vertiente más instrumental. El proceso de racionalización en el sentido weberiano da un paso más adelante. Es ahora cuando aparece el trabajo en un sentido moderno y completamente descargado, o casi, de lo ritual y lo lúdico. Se desarrollan, así, aquellos aspectos contenidos desde sus inicios en el trabajo, como actividad productiva, como la potenciación de un pensamiento y de una actividad teleológicamente orientados y un conocimiento más objetivo del mundo y de uno mismo (LEONTIEV, 1983; LUKÁCS, 2004), todo lo cual ya fue ampliamente teorizado por Marx (1972) y por Engels (1981), como es bien sabido.

Esta mayor especialización que caracteriza al trabajo moderno le otorga a éste una eficacia muy superior a la hora de promover el desarrollo de las fuerzas productivas. Pero la desalienación alcanzada con la racionalización del trabajo se ve contrarrestada por la sumisión del mismo a una dinámica social fuera de control y que embota el libre despliegue de las cualidades humanas (SÈVE, 1989, p. 204-216), así como por la pérdida de los viejos placeres ligados a la dramatización. Junto con la conquista de este control sobre los fundamentos de la propia existencia, el gran desafío actual estriba en un enriquecimiento

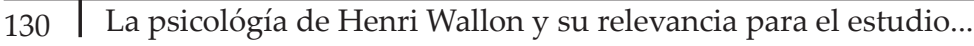


vivencial de la actividad. Se puede ciertamente "resignificar" el trabajo, pero éste ha de preservar esa racionalidad tan arduamente conquistada por el género humano, lo que impone serios límites a esta estrategia. Frente a las acechanzas románticas de un refugio en lo mágico-ritual, el arte y el juego se nos presentan como una alternativa valiosa, en cuanto que modalidades de dramatización controlada y no alienante. Por desgracia, la falta de recursos y de tiempo apenas permite a la mayoría de la población otro acceso a las mismas que no sea el de meros espectadores de sus variantes más vulgarizadas. Pero con ello, la necesidad de un cambio social capaz de alumbrar una liberación del tiempo y un mejor reparto de los recursos se hace todavía más patente. En la medida en que entonces se logre una mayor presencia en la vida cotidiana del arte y el juego y en la medida también en que, hasta cierto punto, se enriquezca con otras dimensiones una actividad laboral necesariamente racionalizada, pero liberada de la presión de un imperativo productivista entendido en términos de rentabilidad mercantil estrecha, podrán abrirse para la humanidad nuevos horizontes para una existencia más plena. En cierto modo, la disociación entre eficacia objetiva y vivencia subjetiva característica de la modernización podría empezar a ser superada Surgiría, así, la posibilidad de una existencia cotidiana enriquecida en cuanto a sus dimensiones estéticas, con la que han soñado algunos clásicos (MARCUSE, 1985, p. 137-184; TROTSKY, 1969, p. 175), volviendo más compleja entonces no sólo la subjetividad del actor individual, sino también la de quienes interactúan con él y la de los meros espectadores externos. El resultado final de este proceso habría de consistir en esa impregnación de la totalidad de la existencia por un flujo pulsional, por un erotismo en un sentido amplio, postulada por Marcuse (1985), a fin de trascender la frecuente reducción del cuerpo, y la mente, a meros instrumentos de trabajo y del erotismo a lo meramente genital. 


\section{Bibliografia}

CASTIEN MAESTRO, Juan Ignacio. Georg Lukács: hacia una antropología marxista del hecho religioso. In: Cadernos Cemarx: Campinas. № 5, p. 65-76, 2008.

ELIADE, Mircea. Herreros y alquimistas. Madrid: Alianza Editorial, 2004.

ENGELS, Friedrich. El papel del trabajo en la transformación del mono en hombre. In: . Introducción a la dialéctica de la naturaleza. Madrid: Editorial Ayuso, 1981.

HUIZINGA, Johan. Homo ludens. Barcelona: Ediciones Altaza, 1997.

LIENHARDT, Godfrey. Divinidad y experiencia. La religión de los dinkas. Madrid: Editorial Akal, 1986.

LEONTIEV, Alexis. El desarrollo del psiquismo. Madrid: Editorial Akal, 1983.

LÉVI-STRAUSS, Claude. La eficacia simbólica. In: LÉVI-STRAUSS, Claude. Antropología Estructural I. Barcelona: Paidós Ibérica, 1987, p. 211-228.

LUKÁCS, Georg. Estética. La peculiaridad de lo estético. Barcelona: Grijalvo, 1967.

. Ontología del ser social. El trabajo. Buenos Aires: Editorial Herramienta, 2004.

MALINOWSKI, Bronislaw. Magia, ciencia y religión. Barcelona: Planeta-Agostini, 1985.

MARCUSE, Herbert. Eros y civilización. Barcelona: PlanetaAgostini, 1985.

MARX. Karl. Manuscritos de economía y filosofía. Madrid: Alianza Editorial, 1972.

PIAGET, Jean. El criterio moral en el niño. Barcelona: Editorial Fontanella, 1974.

132 La psicológía de Henri Wallon y su relevancia para el estudio... 
SÈVE, Lucien. Marxisme et theorie de la personalité. Paris: Les Éditions Sociales, 1989.

THOMPSON, George. Los orígenes de la ciencia y el arte. El surgimiento de la esencia humana. Buenos aires: Editorial Leviatán, 1986.

TROTSKY, León. Literatura y revolución. Otros escritos sobre la literatura y el arte. París: Ruedo Ibérico, 1969.

TURNER, Victor. Un doctor ndembu en acción. In: TURNER, Victor. La selva de los símbolos. Aspectos del ritual ndembu. Madrid: Siglo XXI, 1990, p. 399-440.

VYGOTSKY, Lev. Pensamiento y lenguaje. Barcelona: Paidós, 1995.

WALLON, Henri. La vida mental. Barcelona: Editorial Crítica, 1985.

. Del acto al pensamiento. Buenos Aires: Editorial Psique, 1987.

Henri. La evolución psicológica del niño. Barcelona: Editorial Crítica, 2008

WEBER, Max. Economía y sociedad. Ensayo de sociología comprensiva. México D. F.: Fondo de Cultura Económica, 1964.

ZAZZO, René. Psicología y marxismo. La vida y la obra de Henri Wallon. Madrid: Pablo del Río Editor, 1976. 
